\title{
Corrigendum
}

\section{Vitamin D supplementation and inflammatory and metabolic biomarkers in patients with knee osteoarthritis: post hoc analysis of a randomised controlled trial - Corrigendum}

Shuang Zheng, Bing Wang, Weihu Han, Zhaohua Zhu, Xia Wang, Xingzhong Jin, Benny Antony, Flavia Cicuttini, Anita Wluka, Tania Winzenberg, Dawn Aitken, Leigh Blizzard, Graeme Jones and Changhai Ding

(First published online 25 June 2018)

DOI: 10.1017/S0007114518001174, published online 15 November 2018

Original text and correction

There is a minor mistake in the flowchart (figure 1).

In the Melbourne site, 72 participants was randomised to the placebo group, not 73 .

Original text

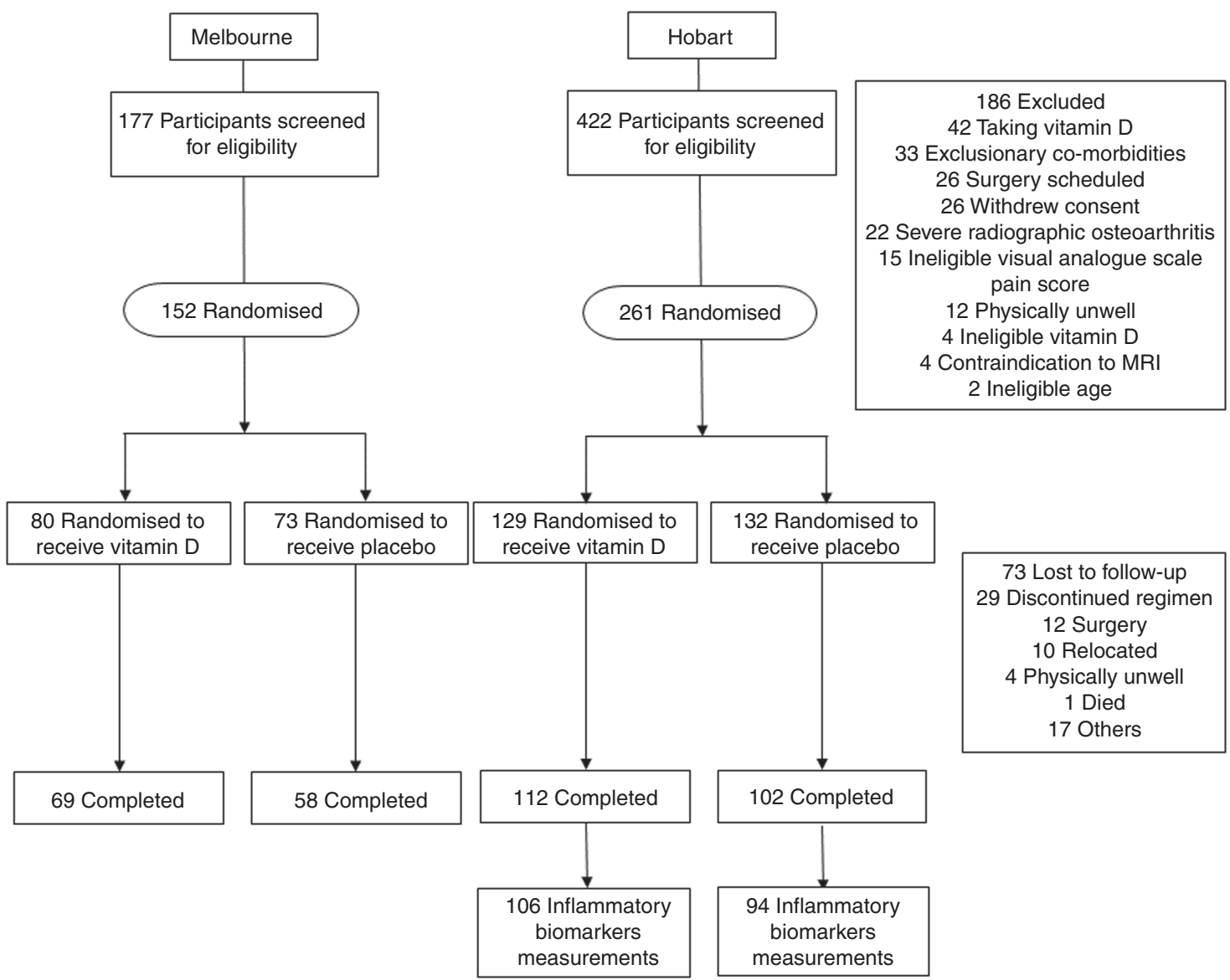


Correction

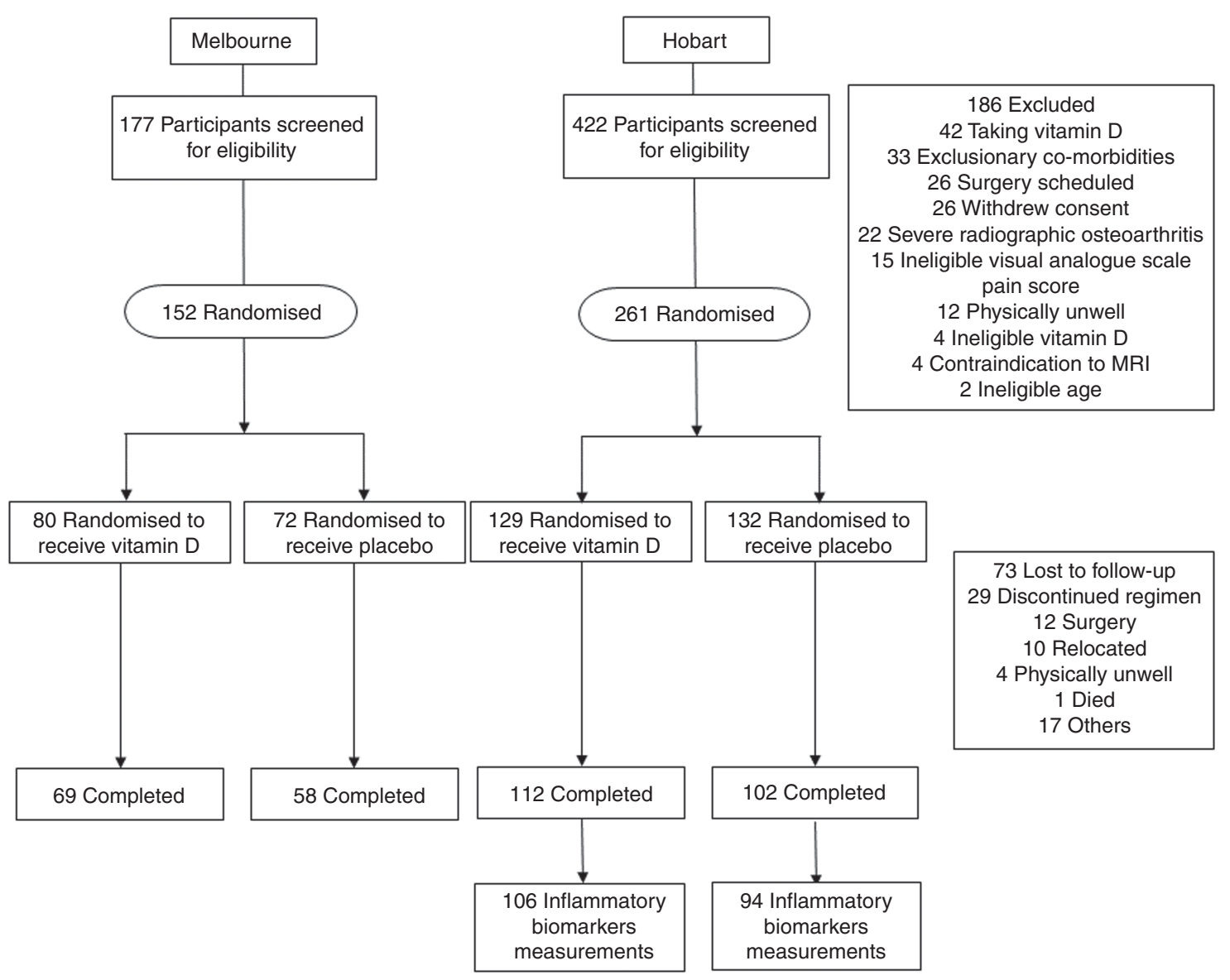

